OPEN ACCESS

Edited by:

Kara Filbey,

The University of Manchester,

United Kingdom

Reviewed by:

Teresa Freire,

Universidad de la República, Uruguay

Lu Huang,

University of Arkansas for Medical

Sciences, United States

*Correspondence:

Sinéad Weldon

s.weldon@qub.ac.uk

Specialty section:

This article was submitted to

Microbial Immunology,

a section of the journal

Frontiers in Immunology

Received: 26 June 2020

Accepted: 10 August 2020

Published: 02 September 2020

Citation:

Ryan S, Shiels J, Taggart CC,

Dalton JP and Weldon S (2020)

Fasciola hepatica-Derived Molecules

as Regulators of the Host Immune

Response. Front. Immunol. 11:2182.

doi: 10.3389/fimmu.2020.02182

\section{Fasciola hepatica-Derived Molecules as Regulators of the Host Immune Response}

\author{
Sinéad Ryan', Jenna Shiels ${ }^{1}$, Clifford C. Taggart', John P. Dalton² and Sinéad Weldon ${ }^{1 *}$ \\ ${ }^{1}$ Airway Innate Immunity Research (AiiR) Group, Wellcome-Wolfson Institute for Experimental Medicine, Queen's University \\ Belfast, Belfast, United Kingdom, ${ }^{2}$ Centre of One Health (COH), Ryan Institute, School of Natural Sciences, National \\ University of Ireland Galway, Galway, United Kingdom
}

Helminths (worms) are one of the most successful organisms in nature given their ability to infect millions of humans and animals worldwide. Their success can be attributed to their ability to modulate the host immune response for their own benefit by releasing excretory-secretory (ES) products. Accordingly, ES products have been lauded as a potential source of immunomodulators/biotherapeutics for an array of inflammatory diseases. However, there is a significant lack of knowledge regarding the specific interactions between these products and cells of the immune response. Many different compounds have been identified within the helminth "secretome," including antioxidants, proteases, mucin-like peptides, as well as helminth defense molecules (HDMs), each with unique influences on the host inflammatory response. HDMs are a conserved group of proteins initially discovered in the secretome of the liver fluke, Fasciola hepatica. HDMs interact with cell membranes without cytotoxic effects and do not exert antimicrobial activity, suggesting that these peptides evolved specifically for immunomodulatory purposes. A peptide generated from the HDM sequence, termed FhHDM-1, has shown extensive anti-inflammatory abilities in clinically relevant models of diseases such as diabetes, multiple sclerosis, asthma, and acute lung injury, offering hope for the development of a new class of therapeutics. In this review, the current knowledge of host immunomodulation by a range of $F$. hepatica ES products, particularly FhHDM-1, will be discussed. Immune regulators, including HDMs, have been identified from other helminths and will also be outlined to broaden our understanding of the variety of effects these potent molecules exert on immune cells.

Keywords: parasite, helminth, helminth defense molecule, Fasciola, FhHDM-1, immunomodulation

\section{INTRODUCTION}

Helminths are parasitic worms classified as flukes, tapeworms or roundworms according to their appearance and the organ in which they reside during infection (1). Diseases caused by helminths constitute the majority of Neglected Tropical Diseases (NTDs) as classified by the World Health Organization (WHO). Helminths are one of the most successful infectious agents in nature as infection is highly prevalent and, as a result, over one billion people are affected worldwide $(2,3)$. One of the most prevalent zoonotic helminth diseases is fascioliasis caused by Fasciola hepatica and 
the larger Fasciola gigantica. This is a major foodborne disease that is currently thought to impact approximately two million people in over 70 countries, with developing countries more severely affected $(4,5)$.

The clinical manifestations of helminth infections are diverse; some infections elicit acute symptoms aligned with pathology caused by worm migration through host tissues, while others may be asymptomatic $(6,7)$. Co-evolution of humans and helminths may have shaped the human immune system as helminths developed sophisticated mechanisms to induce tolerance and evade expulsion by the host enabling them to become successful chronic pathogens (7-9). A range of genomic, transcriptomic, immunomic, glycomic, and proteomic approaches alongside database mining has provided further perspective on hostparasite interactions and led to the identification of various helminth molecules including those within excretory-secretory (ES) products that influence the host inflammatory response (1015). These molecules have garnered much attention with the ultimate aim of exploiting their immunoregulatory mechanisms for the treatment of human diseases $(16,17)$. A number of molecules from $F$. hepatica and other worms are currently under investigation for immunotherapeutic potential and are the main focus of this review.

\section{FASCIOLA HEPATICA}

F. hepatica infection of humans and livestock occurs primarily through the consumption of encysted metacercariae. After ingestion, the metacercariae excyst and become newly excysted juveniles (NEJs) within the duodenum. What follows is the highly pathogenic and infectious migratory stage of $F$. hepatica infection where NEJs cross the intestinal wall to the liver via the peritoneum $(18,19)$. This phase is characterized by inflammation and damage until the NEJs reach the liver bile ducts where they mature into egg-producing adults. Different $\mathrm{T}$ cell responses and cytokine profiles observed in cells from the mesenteric (more IL5) and hepatic lymph (more IL-4) nodes of mice infected with $F$. hepatica suggest that NEJ and hepatic-stage parasites produce different antigens that alter host responses (20). Despite initial inflammation, up to $50 \%$ of infected humans are asymptomatic (21). This is an extraordinary feat for any infectious agent as it indicates the ability to subvert the host immune response which is typically armed to expulse a pathogen. An increased abundance of IgG4 antibodies reactive to antigens (e.g., cathepsin L1) suggests a Th2-driven response is mounted (22); however, much of our knowledge of the immunology of fascioliasis is derived from ruminant animal infection and experimental models using rodents.

\section{Immunology of Fascioliasis}

Helminth infestations often exist as chronic infections as a consequence of a Th2/regulatory response in the host that can support the survival and integrity of host tissue and the parasite $(23,24)$. The immune response mounted during the early stages of fascioliasis is generally regarded as a mixed Th1/Th2 response where cytokines such as IFN $\gamma$, IL-4, IL-10, and TGF$\beta$ are elevated. As the infection progresses, a Th2 response is amplified in conjunction with suppression of Th1 inflammation, thus allowing a prolonged infection that may be dependent on IL-4 (20). In the early stages of bovine F. hepatica infection, both IFN $\gamma$ and IL-10 are increased, corroborating the idea that the initial immune response is mixed (25). Stimulation of peripheral blood mononuclear cells from cattle and sheep with $F$. hepatica ES products showed similar profiles $(26,27)$. In addition, TGF$\beta$ and IL-10 may modulate IL-4 and IFN $\gamma$ in acute and chronic infection, respectively (28).

A cellular source of IL-10 was revealed in murine F. hepatica infection where, among increased macrophages and dendritic cells (DCs) in the peritoneal cavity, there was a significant population of $\mathrm{CD} 25^{+}$Foxp $3^{+}$Treg and inducible Treg cells with the propensity to secrete IL-10 (29). Infection of IL-10 $-/-$ mice showed that IL-4 and IFN $\gamma$ responses were hindered by IL-10 (29). As IL-4 is a critical cytokine observed throughout the pathogenesis of $F$. hepatica infection, the appearance of an abundant population of alternatively activated macrophage (AAM) as early as 7 days after infection of mice in unsurprising (30). AAMs remain in the peritoneum for up to 3 weeks after oral infection with $F$. hepatica metacercariae, highlighting their key role in helminth disease (29). Eosinophilia in the peritoneum is evident in murine liver fluke infection (29) and bovine F. hepatica disease (31), and eosinophils contribute to tissue pathology, particularly in the liver (32). However, in sheep, eosinophils undergo apoptosis suggesting a mechanism by which $F$. hepatica evades the host response (33).

\section{FASCIOLA HEPATICA EXCRETORY-SECRETORY PRODUCTS}

As parasites release ES products during host infiltration, it was deduced that they function as effector molecules capable of modulating the host immune system, enabling parasite survival. Various immunomodulatory molecules have been identified in the ES products of F. hepatica (Table 1) (34). Many of these molecules are advantageous to the helminth and, through manipulation of host immune processes, they facilitate prolonged parasitic infection. Anti-inflammatory effects (Figure 1) have been reported in rodent models of infection and inflammatory disease suggesting the potential for ES product development as therapeutics. However, many of the products discussed below are unique to certain life stages of the liver fluke leaving it difficult to define mechanisms without analysis of their purified or recombinantly produced forms.

\section{Antioxidants}

The antioxidant enzymes thioredoxin peroxidase/peroxiredoxin $(\mathrm{TPx} / \mathrm{Prx})$ in $F$. hepatica ES products detoxify reactive metabolites produced by the host $(35,36)$. F. hepatica ES products induced AAMs and TPx did so without traditional Th2 signaling, i.e., IL-4 or IL-13 $(30,37)$. Administration of purified TPx to BALB/c mice induced a Th2 response as well as expression of Ym-1, TGF- $\beta$, and IL-10, and release of 
TABLE 1 | F. hepatica-derived immunomodulatory molecules.

\begin{tabular}{|c|c|c|c|}
\hline Molecule & Abbreviation & Actions & References \\
\hline Fatty acid binding protein & FaBP, Fh12, Fh15 & Reduction of pro-inflammatory cytokines in LPS-induced models of sepsis & $(44-46)$ \\
\hline Helminth defense molecule & FhHDM-1 & $\begin{array}{l}\text { Inhibits lysosomal acidification and prevents macrophage antigen presentation } \\
\text { Inhibits formation of the NLRP3 inflammasome and thus release of IL-1 } \beta \\
\text { Reduces inflammation in models of multiple sclerosis, type } 1 \text { diabetes, and } \\
\text { allergic asthma }\end{array}$ & $(53,67,69,96)$ \\
\hline Mucin & Fhmuc & $\begin{array}{l}\text { Increases } \mathrm{CD} 11 \mathrm{~b}^{+} \mathrm{MHCll}^{+} \text {macrophage during LPS stimulation and TLR4 } \\
\text { expression is increased in DCs alluding to an increased Th1-type inflammatory } \\
\text { response }\end{array}$ & $(58,59)$ \\
\hline TGF-like molecule & FhTLM & $\begin{array}{l}\text { Inhibits SMAD2/3 signaling and induces a regulatory phenotype in bovine } \\
\text { macrophages }\end{array}$ & $(64)$ \\
\hline Kunitz-type molecule & FhKTM & Decreased inflammatory cytokine secretions in DCs & $(56)$ \\
\hline Glutathione S-transferases & FhGSTs & $\begin{array}{l}\text { Suppress NF-kB pathway stimulation in macrophages and mice with } \\
\text { endotoxemic shock have improved survival in the presence of GST treatment }\end{array}$ & $(41,42)$ \\
\hline Thioredoxin Peroxidase/Peroxiredoxin & TPx/Prx & $\begin{array}{l}\text { Induces } \mathrm{Ym}-1 \text { expression and arginase activity in murine macrophages } \\
\text { Antagonizes actions of ROS and induces AAM phenotype }\end{array}$ & $(30,35,37)$ \\
\hline
\end{tabular}

prostaglandin $\mathrm{E}_{2}\left(\mathrm{PGE}_{2}\right)$ from murine macrophages $(30,37)$. Glutathione S-transferases (GSTs) constitute up to $4 \%$ of the total protein in $F$. hepatica ES products and protect the helminth from free radicals that arise from the host response mounted to expulse the worm (38-40). In DCs, recombinant Sigma-class GST (rFhGST-si) interacts with TLR4 to stimulate IL-6 and MIP2 production and CD40 expression via mitogen-activated protein kinase (MAPK) and NF- $\mathrm{B}$ activity (41). Crucially, rFhGST-si inhibited development of Th17 cells without any interaction with the Th2-type response (41). Although recombinant Mu-class GST isoforms (rFhGST-mu) had no effect on DC activation (41), anti-inflammatory properties of native FhGST-mu (nFhGST-mu) were recently identified in monocytic cells stimulated with a range of TLR agonists and bacteria such as Klebsiella pneumonia, and treatment protected mice from endotoxemia $(41,42)$. In addition, nFhGST-mu suppressed the NF- $\kappa$ B pathway possibly via JAK/STAT signaling proteins and thus it was proposed that nFhGST may be a key antigen utilized by $F$. hepatica to suppress Th1 responses (42).

\section{Fatty Acid Binding Proteins}

F. hepatica fatty acid binding proteins (FaBPs) are a group of chaperones that mediate lipid responses within the cell and are closely linked with inflammation and metabolism (43). Four FaBPs identified in $F$. hepatica are known antioxidants with a nutritive role for the parasite (44). Investigations into their antiinflammatory properties demonstrated that the $12 \mathrm{kDa}$ Fh12 product reduced pro-inflammatory cytokine production in the LPS-induced model of murine sepsis (45). Similarly, the $14.5 \mathrm{kDa}$ Fh15 molecule attenuated production of IL-1 $\beta$ and TNF- $\alpha$ in human THP-1 macrophages (46). In a murine model of sepsis, Fh15 treatment was associated with a significant decrease in circulating cytokines (46).

\section{Cysteine Proteases}

Cysteine proteases constitute approximately $80 \%$ of the ES products from $F$. hepatica and they play major roles throughout infection (47). Five clades of F. hepatica cathepsin L (FhCL) have been identified; three associated with mature adult worms (FhCL1, FhCL2, and FhCL5) and two specific to infective juvenile stage (FhCL3 and FhCL4). Increased secretion of FhCL3 during the initial stages of infection aid the immature NEJ by preventing attachment of host eosinophils (48). Conversely, once the fluke has reached the liver, FhCL1/2 secretions elicit anti-coagulant effects that allow blood feeding for the parasite (49). FhCL1 dampened the Th1 response elicited by administration of the Bordetella pertussis vaccine in mice (50). The decrease in the IFN $\gamma$ response concurs with previous evidence that concurrent $F$. hepatica and $B$. pertussis infection had a decreased Th1-centric response (51). Interestingly, the effects of FhCL1 translated into decreased inflammatory mediators and protective effects in LPS-induced septic shock (52). Although recombinant FhCL1 partially activated DCs via TLR4, these DCs suppressed the development of Th17 cells and did not induce the differentiation of Th2 cells (41). Hypo-responsiveness in peritoneal macrophages stimulated with LPS and FhCL1 indicated that MyD88-independent/TRIF-dependent signaling through cleavage of TLR3 in the endosome was inhibited (52). However, in murine models of type 1 diabetes (T1D) and multiple sclerosis, FhCL1 treatment showed no benefit (53).

\section{Protease Inhibitors}

Kunitz serine protease inhibitors have been identified in the total extract and tegument of $F$. hepatica (54). Interestingly, F. hepatica Kunitz type molecule (FhKTM) has an unique specificity for cysteine proteases (13) and was shown to associate with cathepsin L (55). FhKTM induced a regulatory IL-27dependent phenotype in LPS-stimulated DCs that impaired Th1 and Th17 responses (56).

\section{Mucin-Like Peptides}

Analysis of the NEJ stage of F. hepatica infection led to the discovery of proteins with similarities to mucins $(57,58)$. A synthetic mucin-derived peptide (Fhmuc) increased peritoneal $\mathrm{CD} 1 \mathrm{~b}^{+} \mathrm{MHCII}^{+}$cells in mice exposed to LPS (59). In contrast to other F. hepatica ES products discussed here, but similar 


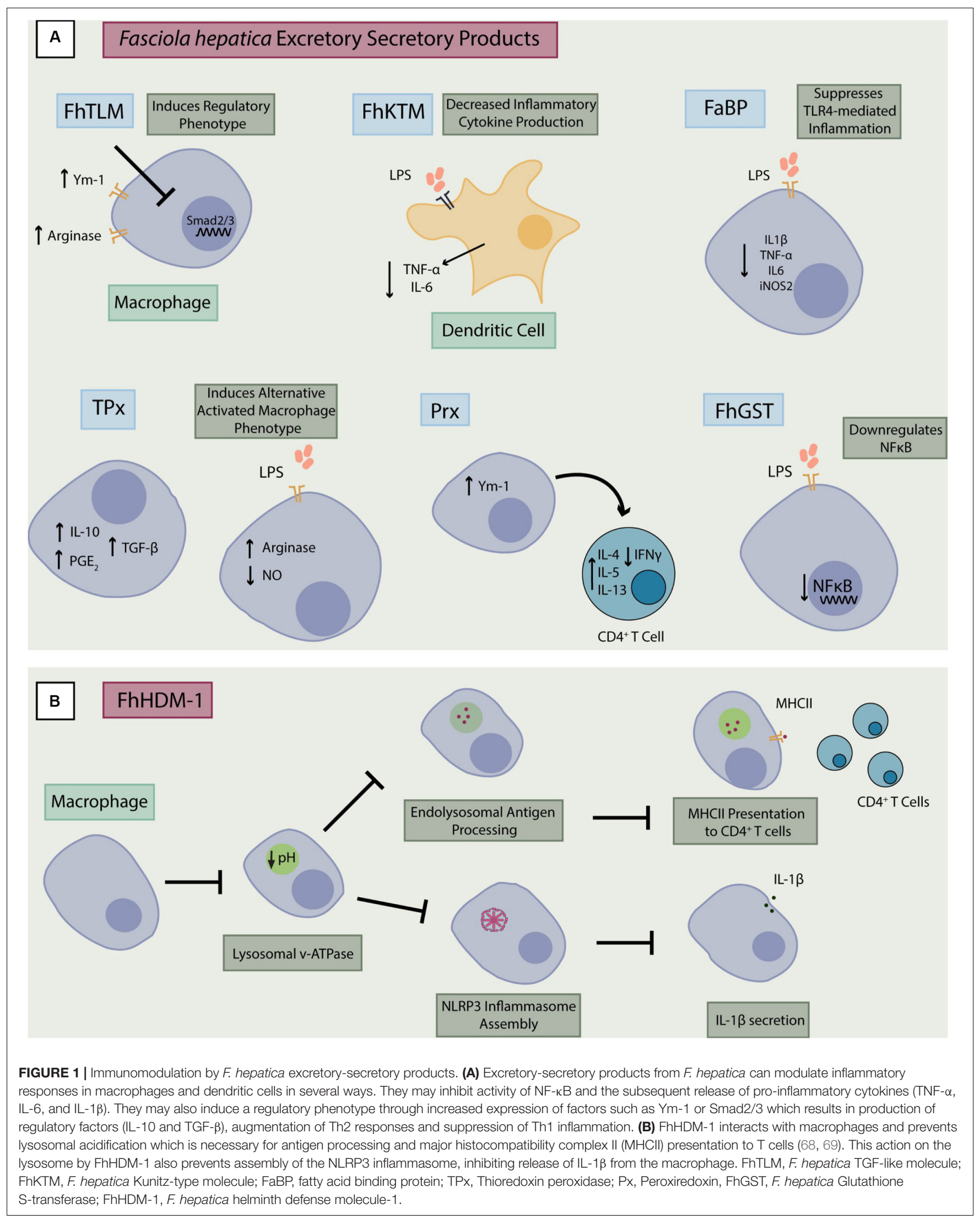


to FhCL1 and FhGST-si (41), Fhmuc elicits pro-inflammatory properties, with increased LPS-induced TLR4 expression in DCs and polarization of the $\mathrm{T}$ cell response (59). This ability of $F$. hepatica to modulate the host immune response may have potential implications for vaccination strategies (59). As F. hepatica ES products contain significant levels of glycans, it is probable that native $F$. hepatica mucin-like peptides undergo glycosylation, which is not represented with the synthetic peptide. Thus, the immunomodulatory effects of native Fhmuc might be different to those described for the synthetic peptide. Indeed, Rodríguez et al. have shown that glycans from $F$. hepatica modulate DC function to induce a Th2 response and suppress Th1 inflammation (60-62).

\section{TGF- $\beta$ Mimics}

Three distinct TGF- $\beta$ homologs were identified in F. hepatica through bioinformatic approaches (63). F. hepatica activin/TGFlike molecule (FhTLM) is highly conserved with other TGF$\beta$ homologs from nematode parasites and has a limited temporal expression pattern across parasite development (63). Recombinant FhTLM supported NEJ viability and development (63). FhTLM may be less potent than mammalian TGF- $\beta$, however, SMAD-2/3 signaling characteristic of the regulatory phenotype was observed in bovine macrophages as well as alternative activation (64).

\section{Helminth Defense Molecules (HDMs)}

During helminth infiltration, increased bacterial infection is common as a consequence of the characteristic tissue damage, although the host inflammatory response remains stable. In schistosomiasis, enteric bacteria are displaced during destruction of the gut; however, symptoms of infection or sepsis are not apparent suggesting the host may be immunosuppressed by the parasite (65). Thus, it was hypothesized that parasites secrete antimicrobial peptides (AMPs) similar to those released by the host as a protective mechanism during infection. Investigation of $F$. hepatica ES products discovered an $8 \mathrm{kDa}$ protein constitutively expressed at all stages of the life-cycle and throughout infection (14). BLAST analyses indicated the sequence was conserved throughout trematode helminth species including Paragonimus westermani, Schistosoma mansoni, and Schistosoma japonicum, and thus was named the helminth defense molecule (HDM). HDMs are classified into three clades: Schistosome HDMs, Fasciola/Asian fluke HDMs and Sm16like molecules. All clade members have a predicted $\mathrm{N}$-terminal peptide and $\alpha$-helical structure as well as a highly conserved, largely hydrophobic C-terminal sequence of approximately 35 residues (14).

\section{F. HEPATICA HELMINTH DEFENSE MOLECULE-1 (FhHDM-1)}

The first discovered HDM was from F. hepatica (FhHDM-1, Figure 1) (14). FhHDM-1 is predicted to have a predominantly $\alpha$-helical secondary structure with a C-terminal amphipathic helix bearing structural and biochemical resemblance to mammalian cathelicidins. Moreover, the 34 residue C-terminal sequence from FhHDM-1 has striking similarity to the human cathelicidin, LL-37 (14, 66, 67). Like LL-37, FhHDM-1 and its conserved C-terminal fragment neutralize LPS preventing TLR4 activation on target cells such as macrophages (14, 68). However, in a murine model of intratracheal LPSinduced acute lung injury, intraperitoneal administration of FhHDM-1 decreased neutrophilic lung inflammation, suggesting mechanisms beyond LPS neutralization may be involved (69). Perhaps unexpectedly, FhHDM and other HDMs did not elicit any antimicrobial activity against different bacteria such as Escherichia coli, Pseudomonas aeruginosa, and Staphylococcus aureus (70). However, in contrast to the mammalian AMPs, they did not induce pore formation in macrophages or the release of lactate dehydrogenase indicating that HDMs do not elicit cytotoxic effects.

The immunomodulatory role of FhHDM-1 was investigated in models of inflammatory disease where ES products showed promise as anti-inflammatories. F. hepatica ES products reduced inflammation in the non-obese diabetic (NOD) T1D mouse model that correlated with an increase in M2 macrophages and Foxp3 ${ }^{+}$Tregs (71). Administration of a synthetic FhHDM-1, but not FhCL1, in NOD mice had a comparable effect with a decreased disease burden characterized by improved survivor function and fewer mice developing diabetes (53). While destruction of pancreatic $\beta$ cells is mediated mainly by autoreactive $\mathrm{T}$ cells (72), inhibition of macrophage activity by FhHDM-1 may elicit positive effects on clinical measurements (53). F. hepatica total extract, ES products and FhHDM-1 have proven beneficial in other autoimmune diseases, for example in the murine experimental autoimmune encephalomyelitis (EAE) model of multiple sclerosis $(53,73,74)$. A predominant theory behind the activity of helminth ES products is their ability to induce a regulatory Th2 response that is often characterized by a M2 (AAM) phenotype in macrophages. While FhHDM-1 reduced TNF- $\alpha$ and IL-6 secretion in LPS-stimulated macrophages (53), there were no significant alterations in surface receptor expression or release of Th1 suppressing cytokines, such as TGF- $\beta$ and IL-10. Furthermore, the auto-antigen specific T cell response remained unchanged in EAE mice that received FhHDM-1 despite showing reduced disease severity (53). This implies that mechanisms other than an induced Th2 response may be responsible for decreased Th1/Th17-mediated pro-inflammatory activity.

FhHDM-1 associates with lipid rafts in the macrophage plasma membrane and is endocytosed (67). Within the macrophage, FhHDM-1 is cleaved by lysosomal cathepsin L to release a C-terminal peptide that can form an amphipathic helix, and this peptide prevented acidification of the lysosomes through inhibition of vacuolar ATPase (vATPase) activity (67). Macrophage process antigens and present them to MHC-II on $\mathrm{CD}^{+} \mathrm{T}$ cells; therefore, impairment of this process via vATPase inhibition would prevent initiation of the adaptive immune response (67). To further define FhHDM1 mechanisms, Donnelly and colleagues hypothesized that inhibition of lysosomal activity in the macrophage (75) 
would impact on inflammasome activity and release of proinflammatory IL-1 $\beta$ (76). Indeed, it was observed that FhHDM-1 reduced IL- $1 \beta$ release in macrophages stimulated with the NLRP3 activator $\mathrm{NanoSiO}_{2}$ and alum. The cysteine protease cathepsin $\mathrm{B}$ is a $\mathrm{pH}$-dependent lysosomal protease involved in activation of the NLRP3 inflammasome (76). As FhHDM-1 inhibits lysosomal acidification, it would inhibit cathepsin B activity and the NLRP3 inflammasome. Replicates of these experiments carried out using the 34 residue C-terminal sequence of FhHDM-1 indicate that these effects on the inflammasome are unique to FhHDM-1 (76). Gene expression analysis of macrophages stimulated with LPS predicted that signaling associated with high-mobility group box-1 (HMGB-1) and IL-17 were attenuated by FhHDM-1 (69). This posed the question of whether FhHDM-1 nay be effective in preventing allergic inflammation, which was subsequently tested in a rodent model of house dust mite-induced asthma (69). In this model, FhHDM-1 treatment reduced neutrophil and eosinophil cell counts, inflammatory markers and airway mucus content (69).

\section{WHAT HAVE WE LEARNED FROM OTHER HELMINTH EXCRETORY-SECRETORY PRODUCTS?}

Immunomodulatory functions and modes of action have been outlined for ES products from several parasites. The filarial worm Acanthocheilonema viteae releases a glycoprotein called ES-62 that can interfere with DC TLR4 expression by inducing autophagosomal degradation (77). By inhibiting mast cell responses, ES-62 and its small molecule analogs prevented the excessive inflammatory response in murine models of asthma (78, 79). However, ES-62 also controls the Th1 response by suppressing NF- $\mathrm{B}$-mediated inflammation in DCs (80). More recently, ES-62 was found to inhibit IL-33/ST2/MyD88 signaling and modulate the pro-inflammatory responses resulting from crosstalk between ST2, FceRI, and TLR4, which may contribute to reported protective effects of ES-62 in chronic models of asthma (81).

Mice with a gastrointestinal infiltration of Heligmosomoides polygyrus have characteristic increases in the number of Treg $\left(\mathrm{CD} 4{ }^{+} \mathrm{CD} 25^{+}\right)$cells. ES products from this parasite potentiate the expression of Foxp3 in $\mathrm{CD}^{+} \mathrm{T}$ cells in vitro through mimicry of TGF- $\beta$ (82). These findings led to the discovery of H. polygyrus TGF- $\beta$ mimic (Hp-TGM) that operates through traditional TGF- $\beta$ signaling pathways leading to polarization of $\mathrm{CD}^{+} \mathrm{T}$ cells with potent suppressive abilities (83). The recently identified $H$. polygyrus alarmin release inhibitor (HpARI) binds to active IL-33 preventing its interaction with ST2 both in murine and human models, and could provide novel therapeutic options in Th2 dominated disease, such as asthma (84).

S. mansoni ES products have pleiotropic effects on the immune response. Factors released from the parasite and its eggs can modulate both Th1 and Th2 responses. For example, IPSE (IL4-producing principle from schistosome eggs) expanded the population of regulatory B cells, which in turn activated Tregs via IL-10 (85) and Schistosoma haematobium IPSE showed therapeutic efficacy in a murine model of hemorrhage in the bladder (86). S. mansoni chemokine binding protein (SmCKBP) is secreted from live eggs and can bind and neutralize the neutrophil chemoattractant CXCL-8 (87). In an experimental granulomatous inflammation model, blocking of live egg smCKBP increased recruitment of neutrophils, macrophage and eosinophils and the size of the egg granuloma, suggesting this ES product may limit leukocyte recruitment to protect the egg (87).

\section{CONCLUDING REMARKS}

The success of F. hepatica infection stems from the worm's ability to modify and manipulate the host immune response. While many years of research have uncovered effective mechanisms by which the parasite can establish a long-term infection, there is much more to be revealed. Investigations in various models of inflammatory disease indicated potential therapeutic benefit of helminths and ES products, however, todate the majority of human clinical trials have not replicated these findings $(11,88-91)$. While small animal models of inflammatory disease provide valuable insights, they often fail to recapitulate the various complex processes at play in human conditions (91). There are a number of factors that need to be considered such as differences in metabolism and the impact of microbiota, particularly on the immune response (92), that may affect efficacy of helminths and their products. Nonetheless, clinical trial outcomes have highlighted the need for a greater understanding of the complexity of changes to the immune response induced by helminths during infection.

A typical helminth genome contains around 50,000 genes, which is much greater than the human genome (approximately 20,000), and it has been proposed that each parasite has undergone specific adaptations for their particular niche (93). Furthermore, as helminths have a multistage life cycle with distinct developmental stages through select tissues and organ systems, they may release distinct molecules within a particular niche (e.g., the intestine or lung) or migratory stages that exert more localized immunomodulatory effects (94), which may be of relevance for targeting tissue-specific inflammation. As recently reviewed by Cortés et al. (95) and van der Zande et al. (9), a number of studies have identified potential roles for helminth-host microbiome interaction in the pathophysiology of helminth disease and in parasitemediated suppression of host inflammation, which may be relevant for the targeting of gut and lung inflammation and (immuno)metabolic dysfunction. In addition to the protein molecules outlined herein, there are a number of other families of helminth immunomodulators, which include various carbohydrate, nucleotide and lipid mediators as well as extracellular vesicles that require further investigation (16). Better understanding of the individual components of helminth ES products and in-depth characterization of their functional roles using defined products may help shed further 
light on their potential efficacy as therapeutic or prophylactic agents for human disease. The discovery and characterization of HDMs from $F$. hepatica and other trematodes may provide one such avenue for novel therapeutics for autoimmune and inflammatory conditions. While further work is needed to better define these molecules, their host targets and their functional effects, there is an expectation that this work will spark the development of novel biotherapeutics for an array of inflammatory diseases.

\section{AUTHOR CONTRIBUTIONS}

All authors listed have made a substantial, direct and intellectual contribution to the work, and approved it for publication.

\section{REFERENCES}

1. Castro GA. Helminths: Structure, Classification, Growth, and Development. Galveston, TX: University of Texas Medical Branch at Galveston. (1996).

2. Bethony J, Brooker S, Albonico M, Geiger SM, Loukas A, Diemert D, et al. Soil-transmitted helminth infections: ascariasis, trichuriasis, and hookworm. Lancet. (2006) 367:1521-32. doi: 10.1016/S0140-6736(06)68653-4

3. Jourdan PM, Lamberton PHL, Fenwick A, Addiss DG. Soil-transmitted helminth infections. Lancet. (2018) 391:252-65. doi: 10.1016/S0140-6736(17) 31930-X

4. Mehmood K, Zhang H, Sabir AJ, Abbas RZ, Ijaz M, Durrani AZ, et al. A review on epidemiology, global prevalence and economical losses of fasciolosis in ruminants. Microb Pathog. (2017) 109:253-62. doi: 10.1016/j.micpath.2017.06. 006

5. Mas-Coma S, Bargues MD, Valero MA. Human fascioliasis infection sources, their diversity, incidence factors, analytical methods and prevention measures. Parasitology. (2018) 145:1665-99. doi: 10.1017/s0031182018000914

6. Harris NL, Loke P. Recent advances in type-2-cell-mediated immunity: insights from helminth infection. Immunity. (2017) 47:1024-36. doi: 10.1016/ j.immuni.2017.11.015

7. Cruz AA, Cooper PJ, Figueiredo CA, Alcantara-Neves NM, Rodrigues LC, Barreto ML. Global issues in allergy and immunology: parasitic infections and allergy. J Allergy Clin Immunol. (2017) 140:1217-28. doi: 10.1016/j.jaci.2017. 09.005

8. Helmby H. Human helminth therapy to treat inflammatory disorders- where do we stand? BMC Immunol. (2015) 16:12. doi: 10.1186/s12865-015-0074-3

9. van der Zande HJP, Zawistowska-Deniziak A, Guigas B. Immune regulation of metabolic homeostasis by helminths and their molecules. Trends Parasitol. (2019) 35:795-808. doi: 10.1016/j.pt.2019.07.014

10. Cwiklinski K, Dalton JP. Advances in Fasciola hepatica research using 'omics' technologies. Int J Parasitol. (2018) 48:321-31. doi: 10.1016/J.IJPARA.2017.12. 001

11. Sotillo J, Toledo R, Mulvenna J, Loukas A. Exploiting helminth-host interactomes through big data. Trends Parasitol. (2017) 33:875-88. doi: 10. 1016/j.pt.2017.06.011

12. McVeigh P. Post-genomic progress in helminth parasitology. Parasitology. (2020) 147:835-40. doi: 10.1017/S0031182020000591

13. Smith D, Tikhonova IG, Jewhurst HL, Drysdale OC, Dvořák J, Robinson MW, et al. Unexpected activity of a novel kunitz-type inhibitor Inhibition of cysteine proteases but not serine proteases. J Biol Chem. (2016) 291:19220-34. doi: 10.1074/jbc.M116.724344

14. Robinson MW, Donnelly S, Hutchinson AT, To J, Taylor NL, Norton RS, et al. Family of helminth molecules that modulate innate cell responses via molecular mimicry of host antimicrobial peptides. PLoS Pathog. (2011) 7:e1002042. doi: 10.1371/journal.ppat.1002042

15. Khaznadji E, Collins P, Dalton JP, Bigot Y, Moiré N. A new multi-domain member of the cystatin superfamily expressed by Fasciola hepatica. Int $J$ Parasitol. (2005) 35:1115-25. doi: 10.1016/j.ijpara.2005.05.001

\section{FUNDING}

This work was supported in part by the Department for the Economy (Northern Ireland; studentships to SR and JS), the Medical Research Council Confidence in Concept Program (SW, JD, and CT), Medical Research Council (MR/T016760/1 and MR/P022847/1; CT and SW). JD was funded by the Science Foundation Ireland (SFI, Ireland) Research Professorship grant 17/RP/5368.

\section{ACKNOWLEDGMENTS}

We apologize to colleagues whose work has not been cited due to space limitations.

16. Maizels RM, Smits HH, McSorley HJ. Modulation of host immunity by helminths: the expanding repertoire of parasite effector molecules. Immunity. (2018) 49:801-18. doi: 10.1016/j.immuni.2018.10.016

17. Kahl J, Brattig N, Liebau E. The untapped pharmacopeic potential of helminths. Trends Parasitol. (2018) 34:828-42. doi: 10.1016/j.pt.2018.05.011

18. Cwiklinski K, O'Neill SM, Donnelly S, Dalton JP. A prospective view of animal and human Fasciolosis. Parasite Immunol. (2016) 38:558-68. doi: 10.1111/ pim. 12343

19. Mas-Coma S, Agramunt VH, Valero MA. Neurological and ocular Fascioliasis in humans. Adv Parasitol. (2014) 84:27-149. doi: 10.1016/B978-0-12-800099$1.00002-8$

20. O’Neill SM, Brady MT, Callanan JJ, Mulcahy G, Joyce P, Mills KHG, et al. Fasciola hepatica infection downregulates Th1 responses in mice. Parasite Immunol. (2000) 22:147-55. doi: 10.1046/j.1365-3024.2000.00290.x

21. Dalton JP, Robinson MW, Mulcahy G, O'Neill SM, Donnelly S. Immunomodulatory molecules of Fasciola hepatica: candidates for both vaccine and immunotherapeutic development. Vet Parasitol. (2013) 195:272-85. doi: 10.1016/j.vetpar.2013.04.008

22. Dowd AJ, Angles R, Parkinson M, Strauss W, Dalton JP, O'Neill SM. Short report: immunodiagnosis of human fascioliasis using recombinant Fasciola hepatica cathepsin L1 cysteine proteinase. Am J Trop Med Hyg. (2017) 60:74951. doi: 10.4269/ajtmh.1999.60.749

23. McNeilly TN, Nisbet AJ. Immune modulation by helminth parasites of ruminants: implications for vaccine development and host immune competence. Parasite. (2014) 21:51. doi: 10.1051/parasite/2014051

24. McSorley HJ, Chayé MAM, Smits HH. Worms: pernicious parasites or allies against allergies? Parasite Immunol. (2019) 41:e12574. doi: 10.1111/pim.12574

25. Clery DG, Mulcahy G. Lymphocyte and cytokine responses of young cattle during primary infection with Fasciola hepatica. Res Vet Sci. (1998) 65:169-71. doi: 10.1016/S0034-5288(98)90171-0

26. Flynn RJ, Mulcahy G. Possible role for toll-like receptors in interaction of Fasciola hepatica excretory/secretory products with bovine macrophages. Infect Immun. (2008) 76:678-84. doi: 10.1128/IAI.00732-07

27. Zhang WY, Moreau E, Hope JC, Howard CJ, Huang WY, Chauvin A. Fasciola hepatica and Fasciola gigantica: comparison of cellular response to experimental infection in sheep. Exp Parasitol. (2005) 111:154-9. doi: 10.1016/ j.exppara.2005.06.005

28. Flynn RJ, Mulcahy G. The roles of IL-10 and TGF- $\beta$ in controlling IL-4 and IFN- $\gamma$ production during experimental Fasciola hepatica infection. Int $J$ Parasitol. (2008) 38:1673-80. doi: 10.1016/j.ijpara.2008.05.008

29. Walsh KP, Brady MT, Finlay CM, Boon L, Mills KHG. Infection with a helminth parasite attenuates autoimmunity through TGF- $\beta$-mediated suppression of Th17 and Th1 responses. J Immunol. (2009) 183:1577-86. doi: $10.4049 /$ jimmunol.0803803

30. Donnelly S, O’Neill SM, Sekiya M, Mulcahy G, Dalton JP. Thioredoxin peroxidase secreted by Fasciola hepatica induces the alternative activation of macrophages. Infect Immun. (2005) 73:166-73. doi: 10.1128/IAI.73.1.166-173. 2005 
31. Bossaert K, Farnir F, Leclipteux T, Protz M, Lonneux JF, Losson B. Humoral immune response in calves to single-dose, trickle and challenge infections with Fasciola hepatica. Vet Parasitol. (2000) 87:103-23. doi: 10.1016/S03044017(99)00177-6

32. Cadman ET, Thysse KA, Bearder S, Cheung AYN, Johnston AC, Lee JJ, et al. Eosinophils are important for protection, immunoregulation and pathology during infection with nematode microfilariae. PLoS Pathog. (2014) 10:1003988. doi: 10.1371/journal.ppat.1003988

33. Escamilla A, Bautista MJ, Zafra R, Pacheco IL, Ruiz MT, Martínez-Cruz S, et al. Fasciola hepatica induces eosinophil apoptosis in the migratory and biliary stages of infection in sheep. Vet Parasitol. (2016) 216:84-8. doi: 10.1016/j. vetpar.2015.12.013

34. Jefferies JR, Campbell AM, Van Rossum AJ, Barrett J, Brophy PM. Proteomic analysis of Fasciola hepatica excretory-secretory products. Proteomics. (2001) 1:1128-32. doi: 10.1002/1615-9861(200109)1:93.3.CO;2-S

35. McGonigle S, Curley GP, Dalton JP. Cloning of peroxiredoxin, a novel antioxidant enzyme, from the helminth parasite Fasciola hepatica. Parasitology. (1997) 115:101-4. doi: 10.1017/S0031182097001170

36. McGonigle S, Dalton JP, James ER. Peroxidoxins: a new antioxidant family. Parasitol Today. (1998) 14:139-45. doi: 10.1016/S0169-4758(97)01211-8

37. Donnelly S, Stack CM, O'Neill SM, Sayed AA, Williams DL, Dalton JP. Helminth 2-Cys peroxiredoxin drives Th2 responses through a mechanism involving alternatively activated macrophages. FASEB J. (2008) 22:4022-32. doi: 10.1096/fj.08-106278

38. LaCourse EJ, Perally S, Morphew RM, Moxon JV, Prescott M, Dowling DJ, et al. The Sigma class glutathione transferase from the liver fluke Fasciola hepatica. PLoS Negl Trop Dis. (2012) 6:e1666. doi: 10.1371/journal.pntd.0001666

39. Brophy PM, Crowley P, Barrett J. Relative distribution of glutathione transferase, glyoxalase I and glyoxalase II in helminths. Int J Parasitol. (1990) 20:259-61. doi: 10.1016/0020-7519(90)90109-Z

40. Chemale G, Morphew R, Moxon JV, Morassuti AL, LaCourse EJ, Barrett J, et al. Proteomic analysis of glutathione transferases from the liver fluke parasite, Fasciola hepatica. Proteomics. (2006) 6:6263-73. doi: 10.1002/pmic.200600499

41. Dowling DJ, Hamilton CM, Donnelly S, La Course J, Brophy PM, Dalton J, et al. Major secretory antigens of the helminth Fasciola hepatica activate a suppressive dendritic cell phenotype that attenuates Th17 cells but fails to activate Th2 immune responses. Infect Immun. (2010) 78:793-801. doi: 10.1128/IAI.00573-09

42. Aguayo V, Valdés Fernandez BN, Rodríguez-Valentín M, Ruiz-Jiménez C, Ramos-Benítez MJ, Méndez LB, et al. Fasciola hepatica GST downregulates NF- $\mathrm{B}$ pathway effectors and inflammatory cytokines while promoting survival in a mouse septic shock model. Sci Rep. (2019) 9:2275. doi: 10.1038/ s41598-018-37652-x

43. Furuhashi M, Hotamisligil GS. Fatty acid-binding proteins: role in metabolic diseases and potential as drug targets. Nat Rev Drug Discov. (2008) 7:489-503. doi: $10.1038 / \mathrm{nrd} 2589$

44. Robinson MW, Menon R, Donnelly SM, Dalton JP, Ranganathan S. An integrated transcriptomics and proteomics analysis of the secretome of the helminth pathogen Fasciola hepatica: proteins associated with invasion and infection of the mammalian host. Mol Cell Proteomics. (2009) 8:1891-907. doi: 10.1074/mcp.M900045-MCP200

45. Martin I, Cabán-Hernández K, Figueroa-Santiago O, Espino AM. Fasciola hepatica fatty acid binding protein inhibits TLR4 activation and suppresses the inflammatory cytokines induced by lipopolysaccharide in vitro and in vivo. $J$ Immunol. (2015) 194:3924-36. doi: 10.4049/jimmunol.1401182

46. Ramos-Benítez MJ, Ruiz-Jiménez C, Aguayo V, Espino AM. Recombinant Fasciola hepatica fatty acid binding protein suppresses toll-like receptor stimulation in response to multiple bacterial ligands. Sci Rep. (2017) 7:5455. doi: 10.1038/s41598-017-05735-w

47. Robinson MW, Tort JF, Lowther J, Donnelly SM, Wong E, Xu W, et al. Proteomics and phylogenetic analysis of the cathepsin L protease family of the helminth pathogen Fasciola hepatica. Mol Cell Proteomics. (2008) 7:1111-23. doi: 10.1074/mcp.M700560-MCP200

48. Carmona C, Dowd AJ, Smith AM, Dalton JP. Cathepsin L proteinase secreted by Fasciola hepatica in vitro prevents antibody-mediated eosinophil attachment to newly excysted juveniles. Mol Biochem Parasitol. (1993) 62:9-17. doi: 10.1016/0166-6851(93)90172-T
49. Mebius MM, Op Heij JMJ, Tielens AGM, de Groot PG, Urbanus RT, van Hellemond JJ. Fibrinogen and fibrin are novel substrates for Fasciola hepatica cathepsin L peptidases. Mol Biochem Parasitol. (2018) 221:10-3. doi: 10.1016/ j.molbiopara.2018.02.001

50. O'Neill SM, Mills KHG, Dalton JP. Fasciola hepatica cathepsin L cysteine proteinase suppresses Bordetella pertussis-specific interferon- $\gamma$ production in vivo. Parasite Immunol. (2001) 23:541-7. doi: 10.1046/j.1365-3024.2001. 00411.x

51. doi: 10.1128/iai.67.10.5372-5378.1999Brady MT, O’Neill SM, Dalton JP, Mills KHG. Fasciola hepatica suppresses a protective Th1 response against Bordetella pertussis. Infect Immun. (1999) 67:5372-8.

52. Donnelly S, O’Neill SM, Stack CM, Robinson MW, Turnbull L, Whitchurch C, et al. Helminth cysteine proteases inhibit TRIF-dependent activation of macrophages via degradation of TLR3. J Biol Chem. (2010) 285:3383-92. doi: 10.1074/jbc.M109.060368

53. Lund ME, Greer J, Dixit A, Alvarado R, McCauley-Winter P, To J, et al. A parasite-derived 68-mer peptide ameliorates autoimmune disease in murine models of Type 1 diabetes and multiple sclerosis. Sci Rep. (2016) 6:37789. doi: 10.1038/srep37789

54. Bozas SE, Panaccio M, Creaney J, Dosen M, Parsons JC, Vlasuk GV, et al. Characterisation of a novel Kunitz-type molecule from the trematode Fasciola hepatica. Mol Biochem Parasitol. (1995) 74:19-29. doi: 10.1016/0166-6851(95) 02478-6

55. Muiño L, Perteguer MJ, Gárate T, Martínez-Sernández V, Beltrán A, Romarís F, et al. Molecular and immunological characterization of Fasciola antigens recognized by the MM3 monoclonal antibody. Mol Biochem Parasitol. (2011) 179:80-90. doi: 10.1016/j.molbiopara.2011.06.003

56. Falcón CR, Masih D, Gatti G, Sanchez MC, Motrán CC, Cervi L. Fasciola hepatica Kunitz type molecule decreases dendritic cell activation and their ability to induce inflammatory responses. PLoS One. (2014) 9:e114505. doi: 10.1371/journal.pone.0114505

57. Cancela M, Ruétalo N, Dell'Oca N, da Silva E, Smircich P, Rinaldi G, et al. Survey of transcripts expressed by the invasive juvenile stage of the liver fluke Fasciola hepatica. BMC Genomics. (2010) 11:227. doi: 10.1186/1471-2164-11227

58. Cancela M, Santos GB, Carmona C, Ferreira HB, Tort JF, Zaha A. Fasciola hepatica mucin-encoding gene: expression, variability and its potential relevance in host-parasite relationship. Parasitology. (2015) 142:1673-81. doi: $10.1017 / \mathrm{s} 0031182015001134$

59. Noya V, Brossard N, Rodríguez E, Dergan-Dylon LS, Carmona C, Rabinovich GA, et al. A mucin-like peptide from Fasciola hepatica instructs dendritic cells with parasite specific Th1-polarizing activity. Sci Rep. (2017) 7:40615. doi: $10.1038 /$ srep40615

60. Rodríguez E, Carasi P, Frigerio S, da Costa V, van Vliet S, Noya V, et al. Fasciola hepatica immune regulates CD11c+ cells by interacting with the macrophage gal/GalNAc lectin. Front Immunol. (2017) 8:264. doi: 10.3389/fimmu.2017. 00264

61. Rodríguez E, Kalay H, Noya V, Brossard N, Giacomini C, Van Kooyk $\mathrm{Y}$, et al. Fasciola hepatica glycoconjugates immuneregulate dendritic cells through the dendritic cell-specific intercellular adhesion molecule-3-grabbing non-integrin inducing T cell anergy. Sci Rep. (2017) 7:46748. doi: 10.1038/ srep46748

62. Rodríguez E, Noya V, Cervi L, Chiribao ML, Brossard N, Chiale C, et al. Glycans from Fasciola hepatica modulate the host immune response and TLRinduced maturation of dendritic cells. PLoS Negl Trop Dis. (2015) 9:e0004234. doi: 10.1371/journal.pntd.0004234

63. Japa O, Hodgkinson JE, Emes RD, Flynn RJ. TGF- $\beta$ superfamily members from the helminth Fasciola hepatica show intrinsic effects on viability and development. Vet Res. (2015) 46:29. doi: 10.1186/s13567-015-0167-2

64. Sulaiman AA, Zolnierczyk K, Japa O, Owen JP, Maddison BC, Emes RD, et al. Trematode parasite derived growth factor binds and exerts influences on host immune functions via host cytokine receptor complexes. PLoS Pathog. (2016) 12:1005991. doi: 10.1371/journal.ppat.1005991

65. Onguru D, Liang YM, Griffith Q, Nikolajczyk B, Mwinzi P, Ganley-Leal L. Short report: human schistosomiasis is associated with endotoxemia and tolllike receptor 2- and 4-bearing B cells. Am J Trop Med Hyg. (2011) 84:321-4. doi: 10.4269/ajtmh.2011.10-0397 
66. Lowther J, Robinson MW, Donnelly SM, Xu W, Stack CM, Matthews JM, et al. The importance of $\mathrm{pH}$ in regulating the function of the Fasciola hepatica cathepsin L1 cysteine protease. PLoS Negl Trop Dis. (2009) 3:369. doi: 10.1371/ journal.pntd.0000369

67. Robinson MW, Alvarado R, To J, Hutchinson AT, Dowdell SN, Lund M, et al. A helminth cathelicidin-like protein suppresses antigen processing and presentation in macrophages via inhibition of lysosomal vATPase. FASEB J. (2012) 26:4614-27. doi: 10.1096/fj.12-213876

68. doi: 10.1128/iai.63.4.1291-1297.1995Larrick JW, Hirata M, Balint RF, Lee J, Zhong J, Wright SC. Human CAP18: a novel antimicrobial lipopolysaccharide-binding protein. Infect Immun. (1995) 63:1291-7.

69. Tanaka A, Allam VSRRVSRR, Simpson J, Tiberti N, Shiels J, To J, et al. The parasitic 68-mer peptide FhHDM-1 inhibits mixed granulocytic inflammation and airway hyperreactivity in experimental asthma. J Allergy Clin Immunol. (2018) 141:2316-9. doi: 10.1016/j.jaci.2018.01.050

70. Thivierge K, Cotton S, Schaefer DA, Riggs MW, To J, Lund ME, et al. Cathelicidin-like helminth defence molecules (HDMs): absence of cytotoxic, anti-microbial and anti-protozoan activities imply a specific adaptation to immune modulation. PLoS Negl Trop Dis. (2013) 7:2307. doi: 10.1371/journal. pntd.0002307

71. Lund ME, O'Brien BA, Hutchinson AT, Robinson MW, Simpson AM, Dalton JP, et al. Secreted proteins from the helminth Fasciola hepatica inhibit the initiation of autoreactive $\mathrm{T}$ cell responses and prevent diabetes in the NOD mouse. PLoS One. (2014) 9:86289. doi: 10.1371/journal.pone.0086289

72. Pugliese A. Autoreactive $\mathrm{T}$ cells in type 1 diabetes. J Clin Invest. (2017) 127:2881-91. doi: 10.1172/JCI94549

73. Finlay CM, Stefanska AM, Walsh KP, Kelly PJ, Boon L, Lavelle EC, et al. Helminth products protect against autoimmunity via innate type 2 Cytokines IL-5 and IL-33, which promote eosinophilia. J Immunol. (2016) 196:703-14. doi: 10.4049/jimmunol.1501820

74. Quinn SM, Cunningham K, Raverdeau M, Walsh RJ, Curham L, Malara A, et al. Anti-inflammatory trained immunity mediated by helminth products attenuates the induction of $\mathrm{T}$ cell-mediated autoimmune disease. Front Immunol. (2019) 10:1109. doi: 10.3389/fimmu.2019.01109

75. Robinson MW, Donnelly S, Dalton JP. Helminth defence moleculesimmunomodulators designed by parasites! Front Microbiol. (2013) 4:296. doi: $10.3389 /$ fmicb.2013.00296

76. Alvarado R, To J, Lund ME, Pinar A, Mansell A, Robinson MW, et al. The immune modulatory peptide FhHDM-1 secreted by the helminth Fasciola hepatica prevents NLRP3 inflammasome activation by inhibiting endolysosomal acidification in macrophages. FASEB J. (2017) 31:85-95. doi: 10.1096/fj.201500093R

77. Eason RJ, Bell KS, Marshall FA, Rodgers DT, Pineda MA, Steiger CN, et al. The helminth product, ES-62 modulates dendritic cell responses by inducing the selective autophagolysosomal degradation of TLR-transducers, as exemplified by PKC $\delta$. Sci Rep. (2016) 6:37276. doi: 10.1038/srep37276

78. Melendez AJ, Harnett MM, Pushparaj PN, Wong WF, Tay HK, McSharry CP, et al. Inhibition of FceRI-mediated mast cell responses by ES-62, a product of parasitic filarial nematodes. Nat Med. (2007) 13:1375-81. doi: 10.1038/ $\mathrm{nm} 1654$

79. Coltherd JC, Rodgers DT, Lawrie RE, Al-Riyami L, Suckling CJ, Harnett W, et al. The parasitic worm-derived immunomodulator, ES-62 and its drug-like small molecule analogues exhibit therapeutic potential in a model of chronic asthma. Sci Rep. (2016) 6:19224. doi: 10.1038/srep19224

80. Lumb FE, Doonan J, Bell KS, Pineda MA, Corbet M, Suckling CJ, et al. Dendritic cells provide a therapeutic target for synthetic small molecule analogues of the parasitic worm product, ES-62. Sci Rep. (2017) 7:1704. doi: 10.1038/s41598-017-01651-1

81. Ball DH, Al-Riyami L, Harnett W, Harnett MM. IL-33/ST2 signalling and crosstalk with Fc $\epsilon$ RI and TLR4 is targeted by the parasitic worm product, ES-62. Sci Rep. (2018) 8:4497. doi: 10.1038/s41598-018-22716-9
82. Grainger JR, Smith KA, Hewitson JP, McSorley HJ, Harcus Y, Filbey KJ, et al. Helminth secretions induce de novo T cell Foxp3 expression and regulatory function through the TGF- $\beta$ pathway. J Exp Med. (2010) 207:2331-41. doi: 10.1084/jem.20101074

83. Johnston CJC, Smyth DJ, Kodali RB, White MPJ, Harcus Y, Filbey KJ, et al. A structurally distinct TGF- $\beta$ mimic from an intestinal helminth parasite potently induces regulatory T cells. Nat Commun. (2017) 8:1741. doi: 10.1038/ s41467-017-01886-6

84. Osbourn M, Soares DC, Vacca F, Cohen ES, Scott IC, Gregory WF, et al. HpARI protein secreted by a helminth parasite suppresses interleukin-33. Immunity. (2017) 47:739-751e5. doi: 10.1016/j.immuni.2017.09.015

85. Haeberlein S, Obieglo K, Ozir-Fazalalikhan A, Chayé MAM, Veninga H, van der Vlugt LEPM, et al. Schistosome egg antigens, including the glycoprotein IPSE/alpha-1, trigger the development of regulatory B cells. PLoS Pathog. (2017) 13:e1006539. doi: 10.1371/journal.ppat.1006539

86. Mbanefo EC, Le L, Pennington LF, Odegaard JI, Jardetzky TS, Alouffi A, et al. Therapeutic exploitation of IPSE, a urogenital parasite-derived host modulatory protein, for chemotherapy-induced hemorrhagic cystitis. FASEB J. (2018) 32:4408-19. doi: 10.1096/fj.201701415R

87. Smith P, Fallon RE, Mangan NE, Walsh CM, Saraiva M, Sayers JR, et al. Schistosoma mansoni secretes a chemokine binding protein with antiinflammatory activity. J Exp Med. (2005) 202:1319-25. doi: 10.1084/jem. 20050955

88. Fleming JO, Isaak A, Lee JE, Luzzio CC, Carrithers MD, Cook TD, et al. Probiotic helminth administration in relapsing-remitting multiple sclerosis: a phase 1 study. Mult Scler J. (2011) 17:743-54. doi: 10.1177/1352458511398054

89. Summers RW, Elliott DE, Urban JF, Thompson RA, Weinstock JV. Trichuris suis therapy for active ulcerative colitis: a randomized controlled trial. Gastroenterology. (2005) 128:825-32. doi: 10.1053/j.gastro.2005.01.005

90. Croese J, Giacomin P, Navarro S, Clouston A, McCann L, Dougall A, et al. Experimental hookworm infection and gluten microchallenge promote tolerance in celiac disease. J Allergy Clin Immunol. (2015) 135:508-16.e5. doi: 10.1016/j.jaci.2014.07.022

91. Evans H, Mitre E. Worms as therapeutic agents for allergy and asthma: understanding why benefits in animal studies have not translated into clinical success. J Allergy Clin Immunol. (2015) 135:343-53. doi: 10.1016/j.jaci.2014. 07.007

92. Tao L, Reese TA. Making mouse models that reflect human immune responses. Trends Immunol. (2017) 38:181-93. doi: 10.1016/j.it.2016.12.007

93. Zarowiecki M, Matt B. What helminth genomes have taught us about parasite evolution. Parasitology. (2015) 142:S85-97. doi: 10.1017/s0031182014001449

94. Schwartz C, Hams E, Fallon PG. Helminth modulation of lung inflammation. Trends Parasitol. (2018) 34:388-403. doi: 10.1016/J.PT.2017.12.007

95. Cortés A, Peachey L, Scotti R, Jenkins TP, Cantacessi C. Helminth-microbiota cross-talk - a journey through the vertebrate digestive system. Mol Biochem Parasitol. (2019) 233:111222. doi: 10.1016/j.molbiopara.2019.111222

96. Alvarado R, O’Brien B, Tanaka A, Dalton JP, Donnelly S. A parasitic helminthderived peptide that targets the macrophage lysosome is a novel therapeutic option for autoimmune disease. Immunobiology. (2015) 220:262-9. doi: 10. 1016/j.imbio.2014.11.008

Conflict of Interest: The authors declare that the research was conducted in the absence of any commercial or financial relationships that could be construed as a potential conflict of interest.

Copyright (c) 2020 Ryan, Shiels, Taggart, Dalton and Weldon. This is an open-access article distributed under the terms of the Creative Commons Attribution License (CC BY). The use, distribution or reproduction in other forums is permitted, provided the original author(s) and the copyright owner(s) are credited and that the original publication in this journal is cited, in accordance with accepted academic practice. No use, distribution or reproduction is permitted which does not comply with these terms. 